\title{
High Resolution Computed Tomography Findings of Interstitial Lung Diseases: A Cross-sectional Study
}

\section{ABSTRACT}

Introduction: Interstitial lung diseases encompass diffuse involvement of parenchymal tissue of lung. Before the use of computed tomography for diagnosis of diseases, radiography was the only existing imaging procedure available for diagnosis of interstitial lung diseases, which had substantial drawbacks when compared to the former.

Aim: To evaluate the pattern of various Interstitial lung diseases by High-Resolution Computed Tomography (HRCT).

Materials and Methods: The study was a descriptive crosssectional, carried out at Department of Radio-Diagnosis of a tertiary care teaching hospital in Solapur. The study was initiated in November 2010 and terminated in July 2012. Ninety patients were included during the study period. Patients having pulmonary symptoms related to any acute/chronic interstitial or diffuse pulmonary disease with significant radiographic findings of chest and willing to participate in the study were recruited in the study. The descriptive statistics (count, frequency and proportion) was applied using Microsoft Excel.

Results: HRCT reports of 10 patients (11\%) were normal. Of the $80(89 \%)$ patients who showed significant HRCT findings, 28 (31\%), 26 (29\%), and 26 (29\%) were diagnosed with interstitial, cystic and airspace abnormality, respectively. Among the patients with Interstitial lung disease, most of the patients were diagnosed with Idiopathic pulmonary fibrosis 21 (75\%) followed by hypersensitivity pneumonitis 5 (18\%).

Conclusion: HRCT is very effective in visualising the distorted architecture of lung parenchyma in patients with acute and chronic presentations of interstitial lung pathology.

Keywords: Hypersensitivity pneumonitis, Idiopathic pulmonary fibrosis, Lymphangitis carcinomatosis, Sarcoidosis

\section{INTRODUCTION}

Interstitial lung diseases encompass diffuse involvement of parenchymal tissue of lung. Before the use of computed tomography for diagnosis of diseases, plain radiography was the only existing imaging procedure available for diagnosis of interstitial lung diseases, which had substantial drawbacks as compared to the former [1]. HRCT, as an imaging procedure was first introduced by Todo $G$ et al., [2]. However, various patterns of diseases of pulmonary parenchymal tissue and use of HRCT to differentiate diffuse pulmonary diseases were first described by Zerhouni EA et al., [3]. Later, these patterns were confirmed for various diffuse lung diseases by a pair comprising of a radiologist and a pathologist [1].

HRCT is a noninvasive test used to distinguish between different types interstitial lung diseases [4]. It is also superior to plain X-ray chest. Before the advent of HRCT, biopsy was necessary for diagnosis of the pathology of lung parenchyma, which has now become needless [1]. Similar studies have been conducted in urban part [5-7]. However, studies conducted in a hospital which also caters the rural popoulation where inequality (e.g., affordability and accesssibility) is seen in health care, are scarce. As these native people rarely undergo advance investigation like HRCT, the present study was planned to address this gap by this research. The present study describes the HRCT findings of interstitial lung diseases in patients referred to department of radiodiagnosis, of a tertiary care teaching hospital in Solapur.

\section{MATERIALS AND METHODS}

The present study is a descriptive cross-sectional conducted in the Department of Radiodiagnosis, of a tertiary care teaching hospital in Solapur. The study was carried out between November 2010 and July 2012. Ninety patients were included during the study period. Patients having pulmonary symptoms related to any acute/chronic interstitial or diffuse pulmonary disease with significant radiographic findings of chest and willing to participate in the study were recruited in the study. All patients who underwent HRCT and satisfied the selection criteria were included in the study.

The patients were scanned by an $3^{\text {rd }}$ generation spiral CT Secura, Philips Medical Systems Pvt., Ltd., in supine position. The chest was scanned from lung apices above to domes of diaphragm below. The digitalised scanogram (antero-posterior) was retrieved by asking the patients to maintain the position in full inspiration. The axial scans were taken at every ten $\mathrm{mm}$ distance. Any abnormalities in the form of opacities were confirmed as normal or abnormal by obtaining scans in prone position. In order to demonstrate, trapped air scans were performed at the deep expiration. The demography (age, gender), history and chest radiograph findings of patients were recorded. The HRCT findings in terms of architectural distortion, interstitial thickening, nodules, ground glass, honeycombing, cyst/ cystic air space, consolidation, bronchiectasis, emphsyema, air trapping, fibrosis, cavity and pleural thickening were noted.

\section{STATISTICAL ANALYSIS}

Descriptive statistical analysis was done using Microsoft Excel 2019.

\section{RESULTS}

In the present study, 90 patients were eligible as per the inclusion and exclusion criteria and were included in the study. Of these, $51(57 \%)$ were males and 39 (43\%) were females. The average age of females (43.2 \pm 20.1 years) was less as compare to that of males (48 \pm 20.4 years)

HRCT reports of 10 patients (11\%) were normal. Of the $80(89 \%)$ patients who showed significant HRCT findings, 28 (31\%) belonged to interstitial, 26 (29\%) belonged to cystic, while 26 (29\%) belonged to airspace abnormality. 
Among the patients with interstitial lung disease, 16 were males and 12 were females. Most of the patients were diagnosed with idiopathic pulmonary fibrosis 21 (75\%) followed by hypersensitivity pneumonitis 5 (18\%). One patient each was diagnosed with sarcoidosis and lymphangitis carcinomatosis [Table/Fig-1].

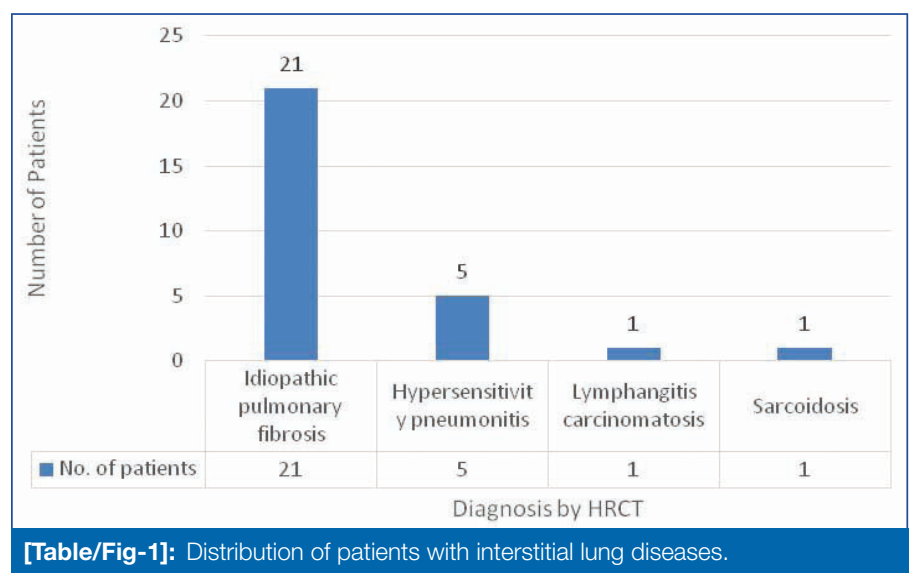

[Table/Fig-2] Distribution of patients accoring to gender, history, chest radiograph and $\mathrm{HRCT}$ findings.

\section{DISCUSSION}

Idiopathic Pulmonary Fibrosis (IPF)

A total of 21 cases of IPF were identified. Thirteen cases were males and eight were females between the age group of 38-80 years. Chest radiographs prior to CT examination showed prominent reticular markings in 19 cases and 2 cases had normal radiographs (10\%) which correlated well with findings decribed by Epler GR et al., [5]. The subpleural region in the lower lobes was the most common area affected and was demonstrated in all patients. The middle lobes were also affected in 14 patients, suggesting that the disease begins in the basal parts of the lung and then progressively involves the rest of the lung. This correlates with the findings of Nakata $\mathrm{H}$ et al., and Müller $N L$ et al., who also described a subpleural basal predominance of the disease [6,7]. Intralobular interstitial thickening producing a fine reticular pattern was identified in 21 patients predominantly in the subpleural location. Such thickening of the intralobular interstitium produces irregular interfaces between the lung and pulmonary vessels, bronchioles and pleura. Thickened interlobular septae with irregular contours as described by Webb WR et al., were noted in seven cases [8]. Fissural thickening with irregular interface was identified in six cases and was attributed to two layers of thickened subpleural interstitium abutting each other in that location.

\begin{tabular}{|c|c|c|c|c|c|}
\hline \multirow{2}{*}{\multicolumn{2}{|c|}{ Variables }} & \multicolumn{4}{|c|}{ HRCT } \\
\hline & & \multirow{2}{*}{$\begin{array}{l}\text { Hypersensitivity pneumonitis } \\
(\mathrm{n}=5) \\
3\end{array}$} & \multirow{2}{*}{$\begin{array}{l}\text { Idiopathic pulmonary } \\
\text { fibrosis }(n=21)\end{array}$} & \multirow{2}{*}{$\begin{array}{l}\text { Lymphangitis carcinomatosis } \\
\qquad(n=1)\end{array}$} & \multirow{2}{*}{$\begin{array}{c}\text { Sarcoidosis } \\
(n=1)\end{array}$} \\
\hline Condar & Females & & & & \\
\hline Gerluel & Males & 2 & 13 & 0 & 1 \\
\hline \multirow{3}{*}{ History } & Cough and dyspnea & 0 & 3 & 0 & 1 \\
\hline & Dyspnea & 5 & 18 & 1 & 0 \\
\hline & Bilateral ill-defined nodules & 0 & 0 & 0 & 1 \\
\hline \multirow{5}{*}{ Chest radiograph findings } & Consolidation and fibrosis & 2 & 0 & 0 & 0 \\
\hline & Consolidation and nodules & 3 & 0 & 0 & 0 \\
\hline & Interstitial lung disease & 0 & 19 & 0 & 0 \\
\hline & Normal & 0 & 2 & 0 & 0 \\
\hline & Reticulonodular shadows & 0 & 0 & 1 & 0 \\
\hline \multirow{2}{*}{ Architectural distortion } & Absent & 3 & 17 & 1 & 1 \\
\hline & Present & 2 & 4 & 0 & 0 \\
\hline \multirow{2}{*}{ Interstitial thickening } & Absent & 5 & 0 & 0 & 1 \\
\hline & Present & 0 & 21 & 1 & 0 \\
\hline \multirow{2}{*}{ Nodules } & Absent & 1 & 21 & 0 & 0 \\
\hline & Present & 4 & 0 & 1 & 1 \\
\hline \multirow{2}{*}{ Honeycombing } & Absent & 1 & 4 & 1 & 1 \\
\hline & Present & 4 & 17 & 0 & 0 \\
\hline \multirow{2}{*}{ Ground glass } & Absent & 5 & 6 & 1 & 1 \\
\hline & Present & 0 & 15 & 0 & 0 \\
\hline Cyst/Cystic air space & Absent & 5 & 21 & 1 & 1 \\
\hline \multirow{2}{*}{ Consolidation } & Absent & 4 & 21 & 1 & 1 \\
\hline & Present & 1 & 0 & 0 & 0 \\
\hline \multirow{2}{*}{ Bronchiectasis } & Absent & 3 & 17 & 1 & 1 \\
\hline & Present & 2 & 4 & 0 & 0 \\
\hline \multirow{2}{*}{ Emphsyema } & Absent & 5 & 18 & 1 & 1 \\
\hline & Present & 0 & 3 & 0 & 0 \\
\hline \multirow{2}{*}{ Air trapping } & Absent & 4 & 21 & 1 & 1 \\
\hline & Present & 1 & 0 & 0 & 0 \\
\hline \multirow{2}{*}{ Fibrosis } & Absent & 5 & 4 & 1 & 1 \\
\hline & Present & 0 & 17 & 0 & 0 \\
\hline Cavity & Absent & 5 & 21 & 1 & 1 \\
\hline \multirow{2}{*}{ Pleural thickening } & Absent & 5 & 17 & 1 & 1 \\
\hline & Present & 0 & 4 & 0 & 0 \\
\hline
\end{tabular}




\begin{tabular}{|l|l|c|c|c|c|}
\hline \multirow{5}{*}{ Other findings } & Beaded major fissures & 0 & 0 & 0 \\
\cline { 2 - 5 } & Fissure thickening & 0 & 3 & 0 \\
\cline { 2 - 5 } & $\begin{array}{l}\text { Irregular interlobular } \\
\text { thickening and mediastinal } \\
\text { lymphadenopathy }\end{array}$ & 0 & 0 & 0 \\
\cline { 2 - 5 } & Irregular linear opacities & 2 & 0 & 0 \\
\cline { 2 - 5 } & Thickened interlobular septae & 0 & 4 & 0 \\
\cline { 2 - 5 } & $\begin{array}{l}\text { Thickened interlobular septae } \\
\text { and fissure thickening }\end{array}$ & 0 & 0 & 0 \\
\hline
\end{tabular}

"Honeycombing" was seen in 15 cases predominantly in the posterior, subpleural lower lung regions, indicating end stage irreversible disease. Such well defined thin walled cystic spaces in several layers and sharing walls have been described by Zerhouni EA et al., and Müller NL et al., and ground glass opacities were seen in 17 cases [3,7]. This represents areas of active septal fibrosis or inflammation as shown by Nishimura $\mathrm{K}$ et al., and is considered as a sign of reversible disease in the absence of fibrosis [9]. However, all cases showing ground glass opacities in the present study had evidence of fibrosis. All these cases with ground glass haziness were considered to have "potentially active" disease as shown by Gay SE et al., and Wells A U et al., [10,11]. Architectural distortion due to fibrosis and traction bronchiectasis was seen in seven cases indicating the late stage of IPF as described by Webb WR et al., [8]. Pleural thickening and emphysematous changes were seen in four and three cases respectively and were consistent with changes described by Strickland B and Strickland NH [12].

Three cases out of 21 had ground glass opacities and patches of consolidation superimposed on reticulation and honeycombing and had presented with acute onset shortness of breath. This represents Diffuse Alveolar Damage (DAD) pattern or Organising Pneumonia (OP) superimposed on the usual interstitial pneumonia pattern as described by Akira $\mathrm{M}$ et al., and Silva $\mathrm{Cl}$ et al., $[13,14]$. These three cases were labelled as acute exacerbations of interstitial lung disease as suggested by Churg A et al., [15]. Most of the cases in this study showed honeycombing, coarse fibrosis, architectural distortion and traction bronchiectasis indicating late stage of the disease. Only three cases presenting with acute shortness of breath showed ground glass opacity and consolidation patches on background of UIP pattern attributed to acute exacerbation of ILD.

\section{Hypersensitivity Pneumonitis}

Five cases of hypersensitvity pneumonitis were diagnosed. Three were females and two were males. All females were cotton farm workers and males were employed in cotton spinning mills. Four patients had history of dyspnea whereas one female had acute onset of shortness of breath. Chest radiographs of three patients showed ill defined consolidation and nodules while that of the remaining two patients showed changes of fibrosis and patchy consolidation. One female cotton farm worker who had acute onset shortness of breath had small rounded opacities and patchy consolidation on HRCT. Similar findings were reported by Silver SF et al., and was labelled as acute stage of hypersensitivity pneumonitis correlating with the acute onset symptoms and occupational background of being a cotton farm worker [16].

Bilateral patchy ground glass opacities were seen on HRCT in all the remaining four patients. Two patients showed ill defined nodular opacities in centrilobular location. Similar findings were reported by Gruden JF et al., and Matar LD et al., $[17,18]$. Silver SF et al., showed that these areas corresponded histologically to interstitial pneumonitis, cellular bronchiolitis and non caseating granulomas [16]. Small JH et al., reported mosaic perfusion in patients with hypersensitivity pneumonitis attributing it to small airway obstruction due to bronchiolitis [19]. Similar finding was demonstrated in one patient. Based on the above findings, two patients were diagnosed as suffering from subacute stage of hypersensitivity pneumonitis. The remaining two patients showed irregular linear opacities, traction bronchiectasis, centrilobular nodules and architectural distortion in mid and upper lobe distribution. These findings correspond to "chronic stage" of disease as described by Matar LD et al., Silva CIS et al., and Silva CIS et al., [18,20,21].

\section{Lymphangitis Carcinomatosis}

One case of lymphangitis carcinomatosis was found. She was a 58-year-old female with occult primary, with involvement of both lungs. Chest radiograph showed reticulonodular opacities. HRCT showed nodular peribronchovascular interstitial thickening similar to findings described by Munk PL et al., and by Bergin CJ and Müller NL $[22,23]$. There was preservation of lung architecture at lobular level without any fibrosis. Irregular thickening of the interlobular fissure was also noted. Other finding observed was mediastinal lymphadenopathy.

\section{Sarcoidosis}

One case of sarcoidosis was found. The patient was a 38-year-old male with biopsy proven sarcoidosis. Chest radiograph showed illdefined bilateral nodules in lungs. The HRCT showed characteristic multiple nodules in relation to the peribronchovascular region, subpleural region, centrilobular region, along the interlobular septa and the fissures. Such perilymphatic distribution of nodules representing the non caseating granulomas of sarcoidosis has been described by Nishimura K et al., and Müller N L et al., [24,25]. The nodules were present bilaterally with upper and mid zone predominance as described by Brauner MW et al., [26]. Both major fissures appeared beaded due to presence of subpleural nodules. "Beaded fissures" have also been described by Müller NL et al., in patients with sarcoidosis [25].

Peribronchial cuffing and nodular septal thickening as described by Nishimura $\mathrm{K}$ et al., Brauner MW et al., and were also noted $[24,27]$. Lymphadenopathy was reported in previous scan, however was not seen in present scan. This indicated that the disease had now progressed to the parenchyma with resolution of the lymphadenopathy. This patient had predominant nodular abnormalities rather than septal thickening and no fibrotic changes. Such changes have been described by Brauner MW et al., as the "active inflammatory" stage of the disease which is potentially treatable or reversible [27]. The patient was asked to continue the steroid therapy.

\section{Limitation(s)}

Owing to adequate number of patients being diagnosed with Idiopathic Pulmonary Fibrosis, the radiological picture of the disease could be delineated among the population of south Maharashtra. However, the number of patients with lymphangitis carcinomatosis and sarcoidosis were too few to generalise the findings.

\section{CONCLUSION(S)}

Idiopathic pulmonary fibrosis affects the subpleural basal regions of the lungs and presents with subpleural intralobular and interlobular 
interstitial thickening, irregular interfaces and fissural thickening. The acute stage of hypersensitivity pneumonitis is characterised by small rounded opacities and consolidation. Lymphangitis carcinomatosis is characterised by interlobular septal thickening with minimal architectural distortion. Peribronchovascular, subpleural and centrilobular nodules with upper and midzone predominance are seen in sarcoidosis. Thus, HRCT visualises the distorted architecture of lung parenchyma in various interstitial pathologies involving the lung. HRCT may thus be recommended to patients where diagnosis by chest radiography and clincal examination is uncertain.

\section{REFERENCES}

[1] Desai SR, Prosch H, Galvin JR. Plain film and HRCT diagnosis of interstitial lung disease. In: Hodler J, Kubik-Huch RA, von Schulthess GK, editors. Diseases of the Chest, Breast, Heart and Vessels 2019-2022: Diagnostic and Interventional Imaging [Internet]. Cham (CH): Springer; 2019 [cited 2020 Sep 19]. (IDKD Springer Series). Available from: http://www.ncbi.nlm.nih.gov/books/NBK553872/.

[2] Todo G, Ito H, Nakano $Y$, Dodo $Y$, Maeda H, Murata K, et al. High resolution CT (HR-CT) for the evaluation of pulmonary peripheral disorders [in Japanese]. Rinsho Hoshasen. 1982;27(12):1319-26.

[3] Zerhouni EA, Naidich DP, Stitik FP, Khouri NF, Siegelman SS. Computed tomography of the pulmonary parenchyma. Part 2: Interstitial disease. J Thorac Imaging. 1985;1(1):54-64.

[4] Walsh SLF, Hansell DM. High-Resolution CT of interstitial lung disease: A continuous evolution. Semin Respir Crit Care Med. 2014;35:129-44.

[5] Epler GR, McLoud TC, Gaensler EA, Mikus JP, Carrington CB. Normal chest roentgenograms in chronic diffuse infiltrative lung disease. $N$ Engl $\mathrm{J}$ Med. 1978;298:934-39.

[6] Nakata H, Kimoto T, Nakayama T, Kido M, Miyazaki N, Harada S. Diffuse peripheral lung disease: Evaluation by high resolution computed tomography. Radiology. 1985;157:181-85.

[7] Müller NL, Miller RR, Webb WR, Evans KG, Ostrow DN. Fibrosing alvelolitis: CT pathological correlation. Radiology. 1986;160:585-88.

[8] Webb WR, Stein MG, Finkbeiner WE, Im JG, Lynch DA, Gamsu G. Normal and diseased isolated lungs: High resolution CT. Radiology. 1988;166:81-87.

[9] Nishimura K, Kitaichi M, Izumi T, Nagai S, Kanaoka M, Itoh H. Usual interstitial pneumonia: Histologic correlation with high resolution CT. Radiology. 1992;182:337-42.
[10] Gay SE, Kazerooni EA, Toews GB, Lynch JP, Gross BH, Cascade PN, et al. Idiopathic pulmonary fibrosis predicting response to therapy and survival. Am J Respir Crit Care Med. 1998;157:1063-72.

[11] Wells AU, Rubens MP, duBois RM, Hansell DM. Serial CT in fibrosing alveolitis: Prognostic significance of initial pattern. AJR. 1993;161:1159-65.

[12] Strickland B, Strickland $\mathrm{NH}$. The value of high definition, narrow section computed tomography in fibrosing alveolitis. Clin Radiol. 1988;39:589-94.

[13] Akira M, Hamada H, Sakatani M, Kobayashi C, Nishioka M, Yamamoto S. CT findings during phase of accelerated deterioration in patients with idiopathic pulmonary fibrosis. AJR Am J Roentgenol. 1997;168:79-83.

[14] Silva Cl, Müller NL, Fujimoto K, Kato S, Ichikado K, Taniguchi H, et al. Acute exacerbation of chronic interstitial pneumonia: High resolution computed tomography and pathologic findings. J Thoracic Imaging. 2007;22:221-29.

[15] Churg A, Müller NL, Silva Cl, Wright JL. Acute exacerbation (acute lung injury of unknown cause) in UIP and other forms of fibrotic interstitial pneumonias. Am J Surg Pathol. 2007;31:277-84.

[16] Silver SF, Müller NL, Miller RR, Lefcoe MS. Hypersensitivity pneumonitis: Evaluation with CT. Radiology. 1987;162:377-81.

[17] Gruden JF, Webb WR, Warnock M. Centrilobular opacitites in lung on HRCT: Diagnostic consideration and pathologic correlation. AJR. 1994;162:569-74.

[18] Matar LD, McAdams HP, Sporn TA. Hypersensitivity pneumonitis. AJR. 2000;174:1061-66.

[19] Small JH, Flower CD, Traill ZC, Gleeson FV. Air trapping in extrinsic allergic alveolitis on computed tomography. Clin Radiol. 1996;51:684-88.

[20] Silva CIS, Müller NL, Churg A. Hypersensitivity pneumonitis: Spectrum of HRCT and pathologic findings. AJR. 2007;188:334-44.

[21] Silva CIS, Müller NL, Lynch DA, Curran-Everett D, Brown KK, Lee KS, et al. Chronic hypersensitivity pneumonitis: differentiation from IPF and NSIP using thin section CT. Radiology. 2008;247:251-59.

[22] Munk PL, Müller NL, Miller RR, Ostrow DN. Pulmonary lymphangitis carcinomatosis: CT and pathologic findings. Radiology. 1988;166:705-09.

[23] Bergin CJ, Müller NL. CT of interstitial lung disease. A diagnostic approach. AJR. 1987; $148: 8-15$

[24] Nishimura K, Itoh $\mathrm{H}$, Kitaichi M, Nagai S, Izumi T. Pulmonary sarcoidosis: Correlation of CT and histopathologic findings. Radiology. 1993;189:105-09.

[25] Müller NL, Kullnig P, Miller RR. The CT findings of pulmonary sarcoidosis, analysis of 25 patients. AJR. 1991;152:1179-82.

[26] Brauner MW, Grenier P, Mompoint D, Lenoir S, de Crémoux H. Pulmonary sarcoidosis: Evaluation with high resolution CT. Radiology. 1989;172:467-71.

[27] Brauner MW, Lenoir S, Grenier P, Cluzel P, Battesti JP, Valeyre D. Pulmonary sarcoidosis: CT assessments of lesion reversibility. Radiology. 1992;182:349-54.

\section{PARTICULARS OF CONTRIBUTORS:}

1. Assistant Professor, Department of Radiology, SMBT Institute of Medical Sciences and Research Centre, Dhamangaon, Nashik, Maharashtra, India.

2. Professor, Department of Radiology, SMBT Institute of Medical Sciences and Research Centre, Dhamangaon, Nashik, Maharashtra, India.

3. Assistant Professor, Department of Radiology, SMBT Institute of Medical Sciences and Research Centre, Dhamangaon, Nashik, Maharashtra, India

4. Professor, Department of Radiology, SMBT Institute of Medical Sciences and Research Centre, Dhamangaon, Nashik, Maharashtra, India.

5. Professor, Department of Radiology, SMBT Institute of Medical Sciences and Research Centre, Dhamangaon, Nashik, Maharashtra, India.

\section{NAME, ADDRESS, E-MAIL ID OF THE CORRESPONDING AUTHOR}

Dr. Ajay Mrutyunjaya Bani,

Assistant Professor, Department of Radiology, SMBT Institute of Medical Sciences

and Research Centre, Dhamangaon, Nashik-422403, Maharashtra, India.

E-mail: ajay3317@hotmail.com
PLAGIARISM CHECKING METHODS: [Jain Het al.]

- Plagiarism X-checker: Oct 17, 2020

- Manual Googling: Dec 21, 2020

- iThenticate Software: Jan 27, 2021 (4\%)

\section{AUTHOR DECLARATION:}

- Financial or Other Competing Interests: None

- Was Ethics Committee Approval obtained for this study? Yes

- Was informed consent obtained from the subjects involved in the study? Yes

- For any images presented appropriate consent has been obtained from the subjects. NA

Date of Submission: Oct 16, 2020 Date of Peer Review: Nov 10, 2020 Date of Acceptance: Dec 23, 2020 Date of Publishing: Apr 01, 2021 